\title{
Simultaneous Determination of Silymarin and Glibenclamide by HPLC-ESI-MS Technique: Method Development and Validation ${ }^{+}$
}

\author{
Iustina-Mihaela Condurache ${ }^{1}$, Anca-Roxana Petrovici ${ }^{2, *}$, Mariana Pinteala ${ }^{2}$ and Lenuta Profire ${ }^{3}$ \\ 1 Department of Biomedical Sciences, “Grigore T. Popa” University of Medicine and Pharmacyof Iasi, \\ 700115 Iasi, Romania; mihaela-iustina.condurache@umfiasi.ro \\ 2 Centre of Advanced Research in Bionanoconjugates and Biopolymers, "PetruPoni" Institute of \\ Macromolecular Chemistry, 41A GrigoreGhicaVoda Alley, 700487 Iasi, Romania; pinteala@icmpp.ro \\ 3 Department of Pharmaceutical Chemistry, "Grigore T. Popa" University of Medicine and Pharmacyof Iasi, \\ 700115 Iasi, Romania; lenuta.profire@umfiasi.ro \\ * Correspondence: petrovici.anca@icmpp.ro; Tel.: +40-740-673-523 or +40-332-880-050 \\ + Presented at the 1st International Electronic Conference on Pharmaceutics, 1-15 December 2020; \\ Available online: https://iecp2020.sciforum.net/.
}

Keywords:HPLC-ESI-MS method; silymarin; glibenclamide; chitosan microparticles

Citation: Condurache, I.-M.; Petrovici, A.-R.; Pinteala, M.; Profire, L. Simultaneous Determination of Silymarin and Glibenclamide by HPLC-ESI-MS Technique; Method Development and Validation. Proceedings 2021, 78, 58 . https://doi.org/10.3390/IECP202008703

Published: date: 1 December 2020

Publisher's Note: MDPI stays neutral with regard to jurisdictional claims in published maps and institutional affiliations.

Copyright: $\left({ }^{\circ} 2020\right.$ by the authors. Licensee MDPI, Basel, Switzerland. This article is an open access article distributed under the terms and conditions of the Creative Commons Attribution (CC BY) license (http://creativecommons.org/licenses/by/4.0/).
(1) Background: The aim of the study was to develop and validate a HPLC-ESI-MS method to simultaneously determine silymarin (Sil) and glibenclamide (Gly) in aqueous solutions, from chitosan-based microparticles. (2) Methods: Sil and Gly, in different concentrations, were loaded into chitosan microparticles using the ionic gelation method [1]. Briefly, the drugs were dissolved in the minimum volume $(0.5 \mathrm{~mL})$ of proper solvent and this solution was thenadded to $3 \mathrm{~mL}$ of $1 \%$ chitosan acetic acid solution. The mixture was stirred at room temperature for $2 \mathrm{~h}$ and then dropped through a syringe needle into $20 \mathrm{~mL}$ of $2 \%$ sodium tripolyphosphate (TPP) solution. After $12 \mathrm{~h}$ of stirring at room temperature, the beads formed were separated from the TPP solution, washed with distilled water, and then dried at room temperature [2]. For identification and quantification of the loaded drugs, a HPLC-ESI-MS method using an Agilent 1200 Series HPLC system coupled to an Agilent 6520 accurate-mass quadrupole time-of-flight (Q-TOF) mass spectrometer, was developed. The separation was made on a Hypersil C18 column with $0.1 \%$ formic acid in MiliQ water (A) and acetonitrile (B) applied in gradient (\% B: $0^{\prime}-25 ; 5^{\prime}-55$; 9'-70; 12'-30; 15'-25). The diode-array detectorDAD separation was monitored at 230, 280, $298,300 \mathrm{~nm}, 0.1 \mathrm{~mL} / \mathrm{min}$ of the elute was directed to ESI/Q-TOF MS, operated at an ionization voltage of $-4000 \mathrm{~V}, 325^{\circ} \mathrm{C}$, with an ion scan value of $50-1000 \mathrm{~m} / \mathrm{z}$ in negative ion mode. The method was validated using recommended parameters [3] and Sil:Gly (1:1) standard solutions. (3) Results: By using the M8 method, the SilARt was registered at $5.41 \mathrm{~min}$, SilB at $5.66 \mathrm{~min}$, and Gly at $10.54 \mathrm{~min}$. The loaded drugs were identified using MS-MS spectra and $\mathrm{m} / \mathrm{z}$ characteristics for all compounds were found in the higher intensity for Rt presented above. The selectivity and precision of the methods are absolute because the Rt for the sample and standard have the same value, and the blank solution proved no interference. The linearity of the answer function is absolute for SilA $\left(R^{2}=1\right)$, and almost absolute for SilB $\left(R^{2}=0.9998\right)$, and Gly $\left(R^{2}=0.9991\right)$. $S / N$ values for all compounds at all studied concentrations maintained similar values. For SilA, we obtained an $\mathrm{LOD}=0.285 \mathrm{mg} / \mathrm{mL}$ and $\mathrm{LOQ}$ $=0.95 \mathrm{mg} / \mathrm{mL}$; for SilB we obtained an LOD $=0.045 \mathrm{mg} / \mathrm{mL}$ and $\mathrm{LOQ}=0.15 \mathrm{mg} / \mathrm{mL}$;for Gly we obtained an $\mathrm{LOD}=0.038 \mathrm{mg} / \mathrm{mL}$ and $\mathrm{LOQ}=1.275 \mathrm{mg} / \mathrm{mL}$. (4) Conclusion: We developed a high resolution HPLC-ESI-MS method to simultaneously determine Sil and Gly in a concentration range of $0.025-1 \mathrm{mg} / \mathrm{mL}$. 
Supplementary Materials: The supplementary file is available online at https://www.mdpi.com/article/10.3390/IECP2020-08703.

Acknowledgments: This research activity was financially supported by AUF-IFA 2019-2020, contract no. 28/2019 and by a grant of the Romanian Ministry of Research and Innovation, CCCDIUEFISCDI, project number PN-III-P1-1.2-PCCDI-2017-0697/13PCCDI/2018, within PNCDI III.

Conflicts of Interest: The authors declare no conflict of interest. The founding sponsors had no role in the design of the study; in the collection, analyses, or interpretation of data; in the writing of the manuscript, and in the decision to publish the results.

\section{References}

1. Constantin, S.M.; Buron, F.; Routier, S.; Vasincu, I.M.; Apotrosoaei, M.; Lupașcu, F.; Confederat, L.; Tuchiluș, C.; Constantin, M.T.; Sava, A.; et al. Formulation and characterization of new polymeric systems based on chitosan and xanthine derivatives with thiazolidine-4-one scaffold. Materials 2019, 12, 558, doi:10.3390/ma12040558.

2. Avram, I.; Lupascu, F.G.; Confederat, L.; Constantin, S.M.; Stan, C.I.; Profire, L. Chitosan microparticles loaded with antidiabetic drugs-Preparation and characterization. Farmacia 2017, 65, 443-448.

3. Nageswara Rao, T. Validation of Analytical Methods. In Calibration and Validation of Analytical Methods-A Sampling of Current Approaches; Stauffer, M.T., Ed.; Intechopen: London, UK, 2018; pp. 131-141, doi:10.5772/intechopen.72087. 